\title{
Educação Ambiental na escola pública: análise a partir da Pedagogia Histórico-Crítica
}

\section{Environmental Education in public schools: an analysis based on Historical-Critical Pedagogy}

Lilian Giacomini Cruz Zucchini

Universidade Estadual de Mato Grosso do Sul (UEMS), Mundo Novo, MS, Brasil. Contato: Iilian.giacomini@uems.br

Resumo: Este estudo apresenta os resultados de uma pesquisa que teve por objetivo analisar, à luz da Pedagogia Histórico-crítica (PHC), a presença da Educação Ambiental (EA) em escolas públicas de Ivinhema, MS, principalmente, sua relação com os conteúdos curriculares. O estudo, que envolveu professores, foi realizado por meio de entrevistas e os dados obtidos foram analisados e organizados em categorias. Os resultados demonstram que, apesar da metodologia de projetos não ter sido citada pelos participantes, o trabalho com a EA nas disciplinas não apresenta outra organização metodológica e os professores não conseguiram relacioná-la com os conteúdos curriculares, nem quais seriam estes e como deveriam ser tratados. Diante disso, reforçamos a necessidade de discutir a EA enquanto atividade nuclear do currículo, repensando-o de forma crítica, de modo que a apropriação dos conteúdos das diferentes áreas do conhecimento possibilite ao educando aprofundar sua compreensão da realidade socioambiental, tendo a sua transformação como objetivo.

Palavras-chave: Educação ambiental; Escola pública; Conteúdo curricular; Pedagogia histórico-crítica.

Abstract: This study presents the results of research that aimed to analyze, in the light of Historical-Critical Pedagogy, the presence of Environmental Education (EA) in public schools in Ivinhema, state of Mato Grosso do Sul, Brazil, especially its relationship with curricular content. The study, which involved teachers, was conducted through interviews and the data obtained were analyzed and organized into categories. The results demonstrate that, although the project methodology was not mentioned by participants, the work with EA in the school subjects does not have another form of methodological organization, and the teachers were unable to relate it to the curricular content, nor what they would be or how they should be addressed. Therefore, we underscore the need to discuss EA as a core activity in the curriculum, by rethinking it critically, so that the appropriation of the contents of the different areas of knowledge can allow students to deepen their understanding of the socio-environmental reality, in which its transformation is the objective.

Keywords: Environmental education; Public school; Curriculum contents; HistoricalCritical pedagogy.

Recebido em: 08/04/2021

Aprovado em: 23/07/2021 


\section{Introdução}

No Brasil, de forma pioneira, a Educação Ambiental (EA) tem garantia constitucional, conforme o disposto no Capítulo VI, artigo 225, da Constituição Federal de 1988. (BRASIL, 1988). Não só o bem ambiental foi consagrado como fundamental, mas também se incumbiu ao poder público "promover a educação ambiental em todos os níveis de ensino e a conscientização pública para a preservação do meio ambiente" (BRASIL, 1988).

De acordo com Frizzo e Carvalho (2018), as políticas públicas são parte dos processos de inserção da EA nas escolas, constituindo a esfera institucional que dá legitimidade a muitos desses processos e orientando os modos como eles se materializam nas escolas. $O$ interesse da sociedade pelas questões ambientais também influencia a elaboração de políticas públicas, a exemplo da legislação já existente, relacionada à EA na educação formal e não formal no Brasil, como a Política Nacional de Educação Ambiental (PNEA), que orienta o desenvolvimento da EA como "prática educativa integrada, contínua e permanente em todos os níveis e modalidades do ensino formal" (BRASIL, 1999). Essa lei regulamenta a previsão feita, já no início da década de 1980, pela Política Nacional de Meio Ambiente (PNMA), em seu artigo 9. ${ }^{\circ}$, que considerou a EA um instrumento da política ambiental (BRASIL, 1981) e o previsto no artigo 225 da Constituição Federal, já citado anteriormente (BRASIL, 1988).

Em nível nacional, além da PNEA (BRASIL, 1999), podemos citar várias outras leis que tematizam e/ou orientam o trabalho com a EA nas escolas, como a própria Lei de Diretrizes e Bases da Educação Nacional (LDB), Lei n 9394/96 (BRASIL, 1996), cujos princípios gerais da Educação apresentados se coadunam com os princípios e objetivos da EA (BRASIL, 2002); os Parâmetros Curriculares Nacionais (PCN), onde o 'Ambiente' é abordado como Tema Transversal; a Lei no 10.172, que instituiu o Plano Nacional de Educação (PNE, 2001/2010) (BRASIL, 2001); e a Resolução no 2, de 15 de junho de 2012, que estabeleceu as Diretrizes Curriculares Nacionais para a Educação Ambiental (DCNEA) (BRASIL, 2012).

No entanto, mais recentemente, estudos como os de Frizzo e Carvalho (2018), Oliveira e Neiman (2020) e Silva e Loureiro (2020), discutem o silêncio da EA nas políticas educacionais atuais: esse silêncio ocorre no Plano Nacional de Educação (PNE), em 2014 (BRASIL, 2014), e na Base Nacional Comum Curricular (BNCC), em 2017 (BRASIL, 2017). Além disso, com a reformulação ministerial do governo Bolsonaro, os setores institucionais responsáveis pela implantação da PNEA, o Departamento de Educação Ambiental (DEA), no Ministério da Educação (MEC) e a Coordenação Geral de Educação Ambiental (CGEA) no Ministério do Meio Ambiente (MMA) foram extintos, desaparecendo do organograma dos dois ministérios, e os quadros técnicos se dispersaram para outros órgãos, esvaziando completamente as equipes. (100 DIAS..., 2019).

Apesar disso, no Estado de Mato Grosso do Sul, nosso local de atuação e onde foi desenvolvido o presente estudo, podemos apontar dois importantes documentos recentes para a inserção da EA nas escolas: a Política Estadual de Educação Ambiental (PEEA/MS), instituída pela Lei n' 5.287, em 13 de dezembro de 2018 (MATO GROSSO DO SUL, 2018), e a Resolução no 3.322 da Secretaria Estadual de Educação (SED), de 13 de setembro de 2017 (MATO GROSSO DO SUL, 2017), que dispõe sobre a oferta da EA nas escolas da Rede Estadual de Ensino de Mato Grosso do Sul. 
Diante do exposto, vimos que a inserção da EA nas escolas brasileira, mesmo diante dos retrocessos recentes, é assegurada por diversas leis, cabendo a nós, portanto, acompanharmos 'se' e 'de que modo' ela tem ocorrido.

O Censo Escolar de 2001, o primeiro que incluiu uma questão sobre EA, constatou que $61,2 \%$ de todas as escolas brasileiras declararam trabalhar com essa temática. Mais tarde, no ano de 2004, esse percentual saltou para 94\% (VEIGA; AMORIM; BLANCO, 2006).

O estudo intitulado $O$ que fazem as escolas que dizem que fazem educação ambiental, realizado pelo Ministério da Educação (MEC) e pelo Instituto Nacional de Estudos e Pesquisas Educacionais Anísio Teixeira (INEP), em escolas de Ensino Fundamental e Médio de todo o país, identificou dados importantes sobre o panorama da EA no Brasil. Segundo os resultados desse estudo, grande parte dos trabalhos educativos ambientais na escola é desenvolvida ou sob a forma de projetos ou por meio da inserção dos temas em disciplinas específicas, em geral nas aulas de Ciências ou Geografia. Os principais temas identificados na pesquisa foram água; lixo e reciclagem; e poluição e saneamento básico (TRAJBER; MENDONÇA, 2006).

Estudos mais recentes, como o de Cruz (2014), fizeram a mesma constatação: em grande parte das escolas, a EA é trabalhada por meio de projetos e, geralmente, estes são desenvolvidos de forma pontual e fragmentada, 'liderados' por professores da área de Ciências e de Biologia. Além disso, a autora observou o que outros autores já indicaram: muitas das atividades em EA são desenvolvidas apenas em datas 'comemorativas', como, por exemplo, no Dia Mundial da Água e no Dia ou Semana do Meio Ambiente, também de forma pontual e isolada, não estabelecendo qualquer ligação com os conteúdos abordados nas disciplinas, e não tendo continuidade no decorrer do ano letivo.

Essa constatação merece reflexão mais aprofundada, pois, de acordo com Barcelos (2007), as dificuldades em se trabalhar com EA nas escolas são decorrentes da rigidez das estruturas curriculares vigentes na maioria das redes de ensino escolar, além das concepções e metodologias que ainda têm como fundamento a ciência moderna cartesiana, positivista, empirista - para a organização do mundo e da própria ciência.

Ainda segundo o autor, se não temos um currículo escolar aberto o suficiente para a discussão de certas temáticas ou para a sua inclusão como conteúdo sem a criação de novas disciplinas, isso não deve servir de obstáculo para que elas não sejam contempladas. Com muita frequência, as questões ambientais são tratadas apressada e superficialmente. O resultado são conclusões "[...] equivocadas e que muito pouco contribuem para um trabalho educativo e de pesquisa, comprometido com o urgente e necessário repensar de nossas representações e práticas de EA" (BARCELOS, 2007, p. 77).

O mesmo autor aponta para o fato de que a hegemonia das atividades educativas realizadas por professores com a EA é constituída de ações fora da sala de aula, ou seja, são realizadas em outros espaços que não o da escola e de seus respectivos conteúdos mínimos ministrados. Não minimizando a importância desses 'outros espaços', fora da escola, para uma educação cidadã e criadora de espaços democráticos e libertários, o autor ainda afirma ser de grande importância e relevância os trabalhos e pesquisas em EA, que tomam como ponto de partida o espaço das relações didático-pedagógicas no cotidiano escolar. Para Barcelos (2007, p. 81), "[...] há que se descobrir formas e metodologias de trabalho de pesquisa nas quais a reflexão sobre as questões ecológicas esteja intrinsecamente relacionada com os conteúdos curriculares das diferentes disciplinas, áreas e/ou níveis do processo educativo escolar". 
A análise de muitos estudos nos traz indicadores de que a EA praticada nas escolas da educação básica ainda é muito frágil (AGUDO, 2013; CRUZ, 2014; FESTOZO, 2015; FIGUEIREDO, 2014; MAIA, 2011; MENDES, 2015; SOUZA, 2014; TEIXEIRA; 2013; TOZONI-REIS; MUNHOZ, 2013, entre outros). Levando em conta toda a pesquisa desenvolvida, veremos que são muitos e variados os determinantes dessa fragilidade, mas se destacam as políticas públicas de EA escolar, a presença de atores externos à escola em seu cotidiano, a organização da escola, a organização dos currículos escolares, as condições de trabalho dos professores e o problema da formação dos professores.

Sobre a inserção da EA na escola no Brasil, sabemos também que ela é marcada por diferentes concepções e práticas que caracterizam diferentes abordagens e/ou tendências. De modo geral, a abordagem crítica tem se apresentado como alternativa às formas mais conservadoras e pragmáticas, conforme discutiram Layrargues e Lima (2014), além de outras, que tratam da dimensão ambiental dos processos educativos.

Sob a perspectiva crítica de EA, aquela que considera o ambiente não somente natural, mas histórico, cultural, social e político, é importante que a inserção da EA na escola se dê pelo currículo, compreendendo-a como uma atividade nuclear da forma como discutiu Saviani (2003). No entanto, segundo Tozoni-Reis (2012, p. 276), "[...] essa inserção pelos currículos é um tema 'delicado' para a EA, em cujas práticas podemos identificar uma tendência em desvalorizar o currículo como possibilidade concreta da realização de práticas críticas e reflexivas".

Essa resistência para a inserção curricular da EA na escola tem dificultado sua inserção mais consistente e, por outro lado, dificultado também a possibilidade de contribuição da EA para a organização de currículos mais ricos e dinâmicos na organização dos conteúdos escolares (TOZONI-REIS, 2012). É importante destacar que inserção curricular não significa a criação de uma disciplina específica, mas a participação da EA como atividade nuclear do currículo, o que nos remete ao papel dos professores e à sua formação, inicial e continuada.

Diante do exposto, é possível perceber que a EA no contexto escolar é uma discussão que ainda está em pauta. Embora muitos pesquisadores tenham se dedicado ao seu estudo, podemos afirmar que a inserção da EA na escola a partir dos conteúdos curriculares é pouco aprofundada e longe de ser um ponto pacífico. Desse modo, alguns questionamentos como: qual é o papel dos conteúdos curriculares na inserção da EA na educação básica? e como e por quem esses conteúdos devem ser definidos e selecionados? constituem nosso problema de pesquisa.

Preocupa-nos a inserção da EA nos currículos escolares e, particularmente, o que nos levou a esta pesquisa, quais seriam os conteúdos curriculares dessa inserção. Em nossas discussões, partimos da afirmação de Saviani (2003), de que a educação escolar tem uma função específica: a de socializar o saber sistematizado pela cultura.

A Pedagogia Histórico-Crítica (PHC), que temos adotado como referencial para pensar uma EA histórico-crítica, radicaliza a ideia de que a educação escolar consiste na socialização e problematização dos conteúdos que emergem da prática social em que professor e aluno estão inseridos, consolidando-se em um processo que possibilite ao aluno se apropriar dos "instrumentos teóricos e práticos necessários ao equacionamento dos problemas detectados na prática social" (SAVIANI, 2008, p. 71). 
Quando falamos em currículo escolar, a partir da PHC, é importante destacar o papel do trabalho na transformação do homem e da natureza e ressaltar que "[...] o trabalho não é qualquer tipo de atividade, mas uma ação adequada a finalidades. É, pois, uma ação intencional" (SAVIANI, 2003, p. 11). Para a sua sobrevivência, o homem transforma a natureza e cria um mundo humano que é, essencialmente, um mundo cultural. Partindo dessa perspectiva, considera-se, portanto, a educação uma atividade exclusivamente humana, assim como o trabalho. Sobre a especificidade do trabalho educativo, Saviani (2003, p.13) nos traz que,

[...] o objeto da educação diz respeito, de um lado, à identificação dos elementos culturais que precisam ser assimilados pelos indivíduos da espécie humana para que eles se tornem humanos e, de outro lado e concomitantemente, à descoberta das formas mais adequadas para atingir esse objetivo.

A partir da função da educação escolar apresentada, podemos compreender a definição de currículo dada pela PHC, pois Saviani (2003) explicita claramente que essa função é identificar os conteúdos que são fundamentais para o constante desenvolvimento e evolução do gênero humano - formação humana omnilateral - e, além disso, quais desses conteúdos produzidos historicamente devem ser selecionados e incluídos no currículo escolar de forma que ele se torne um instrumento para a emancipação do ser humano (MALANCHEN, 2014).

Assim, diante do exposto, que demonstrou a importância da discussão sobre o currículo escolar e seus conteúdos e, considerando os argumentos apresentados em defesa da necessidade de superar as formas fragilizadas com que a EA vem sendo inserida nas escolas, nosso objetivo geral foi analisar o trabalho com a EA nas escolas públicas estaduais do município de Ivinhema-MS, principalmente na sua relação com os conteúdos curriculares, procurando compreender também as concepções dos professores participantes e as dificuldades por eles encontradas para a inserção da EA na escola.

\section{Metodologia}

Com os objetivos definidos, inserimo-nos em um processo de apropriação da realidade do ponto de vista prático e teórico, a fim de compreendê-la, levando-nos a optar por desenvolver uma pesquisa qualitativa.

De acordo com Minayo (2008, p. 21), a pesquisa qualitativa atende a contextos muitos particulares, ocupando-se, nas Ciências Sociais, "com um nível de realidade que não pode ou não deveria ser quantificado", ou seja, "ela trabalha com o universo dos significados, dos motivos, das aspirações, das crenças, dos valores e das atitudes". Segundo a autora, esse conjunto de fenômenos humanos pode ser entendido como parte da realidade social, "[...] pois o ser humano se distingue não só por agir, mas por pensar sobre o que faz e por interpretar suas ações dentro e a partir da realidade vivida e partilhada com seus semelhantes" (MINAYO, 2008, p. 21).

Devechi e Trevisan (2010, p. 150) nos trazem que a pesquisa qualitativa procura "[...] dar conta do lado não perceptível e não captável apenas por equações, médias e estatísticas". Ela surge para mostrar que "[...] o procedimento fundamentado apenas na matemática era insuficiente para pensar a formação do sujeito social que se relaciona com os outros e com o mundo". Assim, o seu diferencial está na inclusão da 
subjetividade, pois não é possível pensá-la sem a participação do sujeito. E, ainda, é qualitativa porque o conhecimento não é indiferente e porque não há relato ou descrição da realidade que não se refira a um sujeito.

Dentre as modalidades da pesquisa qualitativa em educação, próprias para a coleta de dados e para a interpretação de diferentes elementos dos processos pedagógicos estudados, encontramos a pesquisa de campo, que tem a fonte de dados no 'campo' onde ocorrem os fenômenos. Assim, o presente estudo se orientou pelos pressupostos da pesquisa qualitativa em educação e, para atingir os objetivos apresentados, considerou 'campo de pesquisa' o conjunto dos professores da rede estadual - anos finais do Ensino Fundamental e Ensino Médio - que trabalham com EA nas escolas localizadas no município de Ivinhema, MS.

O instrumento de coleta de dados utilizado foi a entrevista semiestruturada, “[...] que combina perguntas fechadas e abertas, em que o entrevistado tem a possibilidade de discorrer sobre o tema em questão sem se prender à indagação formulada" (MINAYO, 2008, p. 64). Esse tipo de entrevista também é conhecido como não diretiva. "A entrevista não diretiva, ou abordagem clínica, é uma forma de colher informações baseadas no discurso livre do entrevistado" (CHIZZOTTI, 2001, p. 92).

Antes de iniciar o trabalho com as entrevistas nas escolas, julgamos pertinente apresentar o projeto de pesquisa para duas professoras da Educação Básica, atuantes nas escolas do município e integrantes do grupo do Programa Institucional de Bolsas de Iniciação à Docência (Pibid), do Curso de Licenciatura em Ciências Biológicas, da Universidade Estadual de Mato Grosso do Sul, onde atuamos. Acreditamos que as professoras poderiam auxiliar no contato com os demais professores nas escolas e com a identificação daqueles que trabalhavam com EA, pois, de acordo com Minayo (2008, p. 66), na entrada do entrevistador em campo, o princípio básico em relação à apresentação é que "[...] uma pessoa de confiança do entrevistado, um líder da coletividade, uma pessoa conhecida e bem aceita, faça a mediação entre ele e o pesquisador".

Estabelecidos os contatos, foram realizadas as entrevistas com nove professores de diferentes disciplinas (que se manifestaram com relação ao trabalho com EA), atuantes nas três escolas públicas estaduais do município. As entrevistas foram gravadas em gravador de voz digital e, posteriormente, transcritas na íntegra.

O projeto desta pesquisa foi analisado e aprovado pelo Comitê de Ética da universidade. Seguindo as orientações do Comitê, todos os professores participantes leram e assinaram o Termo de Consentimento Livre e Esclarecido (TCLE) que Ihes foi apresentado antes do início das entrevistas.

A análise dos dados teve como referência a proposta de Minayo (1998): ordenação dos dados: mapeamento de todos os dados obtidos por meio das entrevistas; classificação dos dados: identificação de categorias de análise; e análise final.

A transcrição das entrevistas na íntegra, e a posterior análise nos permitiu identificar três categorias principais, mas que se relacionam diretamente: Concepções e estratégias para o trabalho com a EA; As dificuldades para a inserção da EA na escola, e EA como atividade nuclear do currículo? 
Os sujeitos da pesquisa não foram identificados pelo nome, mas por um código de acordo com critérios por nós estabelecidos como segue: a letra ' $P$ ', para designar que se trata de um(a) professor(a); um número de 1 a 9 (número de professores entrevistados).

\section{Resultados}

\section{Concepções e estratégias para o trabalho com a EA}

Como parte de nossos objetivos, procuramos identificar e analisar as concepções de EA dos professores participantes da pesquisa. Apesar de muitos estudos já terem se dedicado a levantamentos e análises de concepções de diferentes grupos, colocamos este objetivo, pois acreditamos que o modo como o(a) professor(a) concebe a EA pode refletir diretamente sobre sua prática, sobre como a organiza e desenvolve suas ações junto aos alunos na escola e como as insere - ou não - no currículo escolar.

De acordo com Layrargues e Lima (2014, p. 25), pode-se dizer que o campo da EA "é composto por uma diversidade de atores, grupos e instituições sociais que compartilham um núcleo de valores e normas comuns". No entanto, esses atores também são diferentes em suas concepções sobre o meio ambiente e a questão socioambiental, além dos posicionamentos políticos, pedagógicos e epistemológicos que defendem para discutir os problemas ambientais (LAYRARGUES; LIMA, 2014), daí a importância de identificar as concepções dos professores participantes da pesquisa.

Ainda, segundo os autores, isso significa que, na prática, há diversos caminhos possíveis para se trabalhar a EA. A partir de um conjunto complexo de circunstâncias, alguns atores escolhem um determinado caminho, outros escolhem um caminho diferente:

[...] uns acreditam ser determinante o desenvolvimento da sensibilidade na relação com a natureza, outros entendem que é fundamental conhecer os princípios ecológicos que organizam a vida. Alguns têm forte expectativa no autoconhecimento individual e na capacidade de mudança do próprio comportamento em relação à natureza, outros estão seguros que é preciso contextualizar o problema ambiental com suas dimensões sociais e políticas, entre outras possibilidades. (LAYRARGUES; LIMA, 2014, p. 28).

Em um estudo sobre as macrotendências político-pedagógicas da EA, Layrargues e Lima (2014) nos apresentam três tendências principais: a conservacionista, a pragmática e a crítica.

Justificada a importância de se compreender a existência de diferentes concepções de EA e a necessidade de identificá-las entre os professores participantes da pesquisa, apresentamos a seguir os dados obtidos por meio das entrevistas.

Quando questionados sobre o que é a EA, a maioria dos professores participantes a definiu com termos como: conscientização, preservação, cuidado, recursos naturais.

De acordo com Layrargues (2014, p. 27), inicialmente, concebia-se a EA como um saber e uma prática fundamentalmente conservacionista, ou seja, "[...] uma prática educativa que tinha como horizonte o despertar de uma nova sensibilidade humana para com a natureza, desenvolvendo-se a lógica do 'conhecer para amar, amar para preservar', orientada pela conscientização 'ecológica'[...]. Essa representação 
simplificadora, e a decorrente prática, foram identificadas nas falas dos professores entrevistados. Vejamos um exemplo:

Pra mim, Educação Ambiental é tudo que tem a ver com o ambiente, com a conscientização da questão ambiental, dos recursos naturais, da preservação desses recursos naturais, pra mim tem a ver com a Educação Ambiental. [P9].

A vertente pragmática, "[...] expressão do ambientalismo de resultados, do pragmatismo contemporâneo e do ecologismo de mercado que decorrem da hegemonia neoliberal" (LAYRARGUES; LIMA, 2014, p. 30) também foi identificada em outras falas. Vejamos uma delas:

Educação Ambiental seria a identificação dos impactos ambientais e solucionar com recursos, novas tecnologias. Ensinar a eles sobre os problemas ambientais que existem e como, as medidas para solucionar ou diminuir a produção de gases, por exemplo. [P3].

A visão crítica da EA - ambiente articulado às condições sociais, às relações de poder e ao processo de dominação -, na qual podemos destacar as concepções crítico-transformadoras, não foi verificada em nenhuma das falas dos professores participantes.

Sobre as concepções de EA dos professores entrevistados, podemos dizer que elas aparecem muito mais como representações sociais, como discute Reigota (1995), e confirmam o que outros estudos, como o de Tozoni-Reis e Munhoz (2013) identificaram: apesar de a sociedade exigir que os professores, por sua função social, tenham concepções mais elaboradas acerca dos saberes escolares, incluindo, as questões socioambientais, suas concepções são muito mais representações difusas do que concepções elaboradas acerca do ambiente e da EA, gerando uma concepção convencional da educação em geral e da EA em particular.

Com a identificação das concepções de EA, seguimos com o levantamento de dados, perguntando aos professores participantes quais seriam as estratégias, teóricas e práticas, mais adequadas para a sua inserção na escola. Entre os nove professores participantes, a maioria citou a aula prática como a principal estratégia utilizada por eles para trabalhar a EA na escola. Vejamos algumas falas:

Eu gosto de simular, igual eu falei pra você, a chuva ácida, fiz com eles um experimento, eu simulei a chuva ácida pra eles, então peguei um pouquinho lá do enxofre, fiz a queima do enxofre num ambiente fechado, num tubo, e depois eu trabalhei os problemas que essa acidez pode causar no solo, falei um pouquinho de calagem, essa correção, então, eu gosto de associar à prática porque o teórico em si, eu acho que não é absorvido muito, eu gosto de ser um pouco visual. [P3].

Eu acredito que estratégias todas são válidas, todas são eficientes, agora, existem as que chamam mais a atenção do aluno do que outras, eu acredito que falar em sala de aula é eficiente, você fala, tenta conscientizar o aluno, mas quando você mostra ao aluno, você fazer uma visita, uma aula prática, ou trazer alguém de fora, ele sempre parece que valoriza mais do que quando é o professor que está falando [...] [P8]

Outros professores citaram estratégias teóricas e práticas, e a necessária articulação entre elas. Vejamos um exemplo: 
Acho que o teórico é a leitura, a forma que eu gosto de trabalhar é com a leitura de artigo, tanto artigo científico mesmo, que eu pego na internet, como artigo de revista, principalmente a Revista do Biólogo, do CRBio 1, que eu gosto muito. [...] Então, a principal forma é a leitura, é fazer eles [sic] lerem, porque só falar eles não assimilam. Acho que esse é o primeiro ponto. O segundo, em relação à prática, aí é aula prática, aula de campo dentro do que dá pra fazer, o que não é muita coisa, porque a gente não tem muito recurso e principalmente, a gente não tem muito tempo [...]. [P2]

As respostas com relação às estratégias utilizadas para a inserção da EA na escola nos a pontam que os professores entrevistados parecem não recorrer mais à metodologia de projetos para tal. Suas respostas nos permitem inferir que o trabalho com a EA na escola tem ocorrido mais no 'interior das disciplinas', ou seja, no desenvolvimento dos conteúdos destas, do que sob a forma de projetos extracurriculares.

De fato, percebemos uma preferência às atividades práticas pela maioria dos professores entrevistados, sejam elas dentro ou fora da escola, no entanto, não fica evidente a avaliação da atividade de ensino utilizada, a forma de preparo das atividades, como se dá a participação dos estudantes e do próprio professor e, verifica-se, nas descrições dos professores, certo espontaneísmo em seus procedimentos, diferente de um trabalho intencionalmente planejado.

No que diz respeito à superação desse espontaneísmo na ação pedagógica, quando: "[...] o educador não percebe a determinação histórica do conhecimento, ou seja, não percebe os instrumentos e as técnicas de que se utiliza como tendo nascido de uma necessidade humana" (MELLO, 2000, p. 91), essa atitude espontânea frente à prática pedagógica limita o processo educativo e cerceia o desenvolvimento da liberdade necessária à realização de uma prática docente humanizadora (MAGALHÃES, 2019). Dizemos isso porque ainda há um discurso equivocado de que as aulas práticas são mais importantes e/ou essenciais para a compreensão dos conteúdos. Mas será que existe alguma prática sem teoria?

Saviani (2003, p. 107) nos traz a necessidade de pensar a prática a partir da teoria, pois esta será tanto mais coerente e consistente quanto mais consistente e desenvolvida for a teoria que a embasa, e: “[...] uma prática será transformada à medida que exista uma elaboração teórica que justifique a necessidade da sua transformação e proponha as formas da transformação".

\section{As dificuldades para a inserção da EA na escola}

Quando questionados sobre quais seriam as principais dificuldades para a inserção da EA na escola, a maioria dos professores entrevistados citou a "falta de tempo", seguido da "falta de conhecimento/informação, tanto dos alunos, como dos professores" e a "dificuldade de conscientização dos alunos". Vejamos algumas de suas falas:

Falta de conhecimento. Da equipe toda, dos professores todos, coordenação, direção. Eu acho que a grande maioria das pessoas ainda não sabe da importância de se trabalhar a Educação Ambiental e de educar a população pra essa situação que a gente vive hoje [...] [P2]

Eu acho que é a questão um pouco do tempo, nosso currículo é extenso, eu não consigo ficar focado somente na parte ambiental [...]. Em relação ao aluno, seria falta de informação, se você entrega um artigo, nem todos vão ler esse artigo, a leitura para muitos é chata. [P3] 
A escola é muito burocratizada, os professores, tadinhos de nós, nós parecemos o coelhinho da Alice, têm tanta coisa pra fazer e é tão pouco tempo, então é: "tô atrasado, tô atrasado, tô atrasado", e vai se jogando responsabilidades para a escola e essas responsabilidades, elas nunca vão ser totalmente atingidas, né? Eu não consigo fazer tudo o que eu tenho que fazer e aí não me sobra tempo para pensar a educação sob a perspectiva de ação e significação, que a educação tem que ter significação, educação sem significação não tem [...]. Então, na escola eu acredito que essa falta de tempo do professor, essa sobrecarga do professor é uma problemática. [P5]

A 'falta de tempo', apontada pelos professores entrevistados, indica-nos a necessidade de uma discussão mais aprofundada sobre o currículo, uma vez que, entre outras coisas, essa 'falta de tempo' está vinculada à necessidade e à preocupação com o cumprimento das atividades propostas pelo Currículo do Estado de Mato Grosso do Sul ('Referencial Curricular' ou 'Currículo de Referência'), planejado e reorganizado recentemente para atender às orientações da BNCC. Este referencial se consolidou como 'um orientador da prática pedagógica', trazendo orientações metodológicas para o ensino e um planejamento para o desenvolvimento de cada conteúdo, propondo, inclusive, um número de aulas destinadas para cada um.

A sobrecarga de atividades, como um excesso de deveres atribuídos aos professores e à equipe gestora diariamente, revela-se um dos mais importantes obstáculos no processo de inserção da EA na escola, como pudemos observar em uma das falas apresentadas. A esse respeito, Facci (2004, p. 249) afirma que, "[...] quando o sentido pessoal do trabalho do professor se separa do significado dado socialmente, pode-se considerar esse trabalho alienado e este pode descaracterizar a prática educativa escolar". Ou seja, conforme discute Basso (1998), a prática educativa, entendida como aquela que tem uma função mediadora entre os alunos e os conhecimentos e instrumentos culturais que serão apropriados, descaracterizamse.

\section{EA como atividade nuclear do currículo?}

Procurando identificar se os professores participantes estabelecem relação entre a EA e os conteúdos curriculares, perguntamos a eles qual seria o papel destes para a EA. Vejamos algumas respostas:

Nós temos um currículo que fala sobre a questão da Educação ambiental, nós só não temos conteúdos no livro didático, conteúdos preparados a nível de [sic] Estado, a nível [sic] regional para ser trabalhado na escola, a gente não tem esse aparato pra ser trabalhado na escola, deveria ter, deveria ser formulado alguma coisa a nível de [sic] estado, a nível [sic] regional, a nível de [sic] Brasil, nós temos biomas riquíssimos e que os alunos nem conhecem a importância deles, a riqueza então deveria ter algo mais específico pelo menos a nível [sic] didático de ciências pra ser trabalhado. [P1]

É, os conteúdos curriculares eles têm papel importante na formação da personalidade, na formação da consciência do estudante, eu acredito que mais importante que isso é ele trazer já de casa esse pensamento, muitos alunos, é, não têm essa consciência, você fala sobre a questão de desperdício de água, a questão de jogar lixo na rua e eles acham engraçado porque eles não tiveram essa formação em casa ou não têm, ou de alguma forma, eu não sei que forma que isso é abordado em casa, mas alguns alunos só têm essa noção quando chegam à escola, então, os conteúdos, independente de qual, todos eles têm um grande papel, um papel importante na formação do estudante. [P9] 
Conteúdo curricular é aquele conteúdo que a gente deve trabalhar com o aluno, que a gente deve pautar nossa aula, organizar aula e preparar aula em cima daquilo. Normalmente, ele vem predestinado, ou, dentro da escola a gente faz um remanejamento dentro daquilo que a gente acredita que é o ideal, mas sem mudar alguma coisa também, sem sair muito de uma determinada linha. [P7]

Com base nas respostas dos professores, que não apresentaram concepções muito claras sobre os conteúdos curriculares, nem sua relação com a EA e sobre qual seria o papel destes para a EA, faz-se necessária uma discussão a respeito, a partir da PHC.

Segundo Marsiglia (2011), a educação escolar é valorizada, pois tem o papel de garantir os conteúdos que permitam aos alunos compreender e participar da sociedade de forma crítica, além de promover o diálogo com os professores, o respeito ao seu desenvolvimento psicológico, incorporando à sua experiência inicial o universo cultural acumulado historicamente pela humanidade (SAVIANI, 2008). Cabe à educação escolar, portanto, identificar os elementos culturais que devem ser assimilados e as formas mais adequadas a essa assimilação.

Sobre a identificação desses elementos culturais, a escola deve socializar o conhecimento construído historicamente, possibilitando aos educandos o acesso à cultura erudita (SAVIANI, 2003), a desmistificação da realidade e a compreensão da totalidade que se desvela por detrás da aparência dos fenômenos.

Com relação às formas de transmissão/assimilação do conhecimento, é importante fazer a distinção entre o principal e o secundário, ou seja, selecionar dentre a produção humana, traduzindo em saber escolar, aquilo que é primordial, tornando esse conhecimento um conteúdo de ensino do currículo escolar. A esse respeito, Saviani (2008, p. 55) nos traz:

Por que esses conteúdos são prioritários? Justamente porque o domínio da
cultura constitui instrumento indispensável para a participação política das
massas [...]. O dominado não se liberta se ele não vier a dominar aquilo que
os dominantes dominam. Então, dominar o que os dominantes dominam é
condição de libertação.

Diante do exposto, que relação haveria entre os conteúdos curriculares e a EA? Entendemos que a inserção da EA na escola deve ocorrer pelo currículo, compreendendo-a como uma atividade nuclear, isto é, uma atividade essencial que a escola não pode deixar de desenvolver. Compreender a EA como uma atividade nuclear do currículo significa que ela deve ser trabalhada no interior das disciplinas já existentes na escola e, a partir da problematização dos seus conteúdos, que são, portanto, a base para o seu desenvolvimento.

No entanto, de acordo com Tozoni-Reis (2012), sem uma proposta clara de inserção curricular, a EA vem constituindo-se em um tema "periférico" do currículo escolar, sendo trabalhada como atividade extracurricular.

Observa-se que as iniciativas para sua inserção não têm sido uma tarefa fácil para o campo da EA. Algumas das respostas dadas pelos professores participantes deste estudo indicam que as atividades desenvolvidas nas escolas são fragmentadas, pontuais e prático-utilitaristas, desvalorizando o currículo.

Algumas das questões mais polêmicas e, ao mesmo tempo, mais importantes para a educação escolar são a seleção e a organização dos conteúdos que os alunos devem aprender. Se a EA compreendida como atividade nuclear do currículo é aquela 
que se desenvolve a partir dos conteúdos curriculares das disciplinas, quais seriam, então, esses conteúdos? Como são selecionados? Como podem ser trabalhados?

Quando questionados sobre quais seriam os conteúdos curriculares fundamentais para a EA escolar, a maioria dos professores apontou conteúdos variados dentro das disciplinas que ministram, mas sem muitos critérios que pudessem justificar tais escolhas. Vejamos:

Meus Deus, todos, olha é que sem entender a parte do primeiro ano né, que é o estudo de célula e funcionamento de célula, fica difícil entender o resto, então acaba que tudo tem importância, mas, assim, diretamente, falar diretamente ligado à educação ambiental é o conteúdo básico do segundo ano todo, que é o estudo dos seres vivos [...] [P1]

Olha, é, depende, porque depende da série né, porque, por exemplo, eu acho que dá pra trabalhar mais no sexto, no sétimo, no segundo ano do Ensino Médio, são os que a gente pode trabalhar mais, só que a questão ambiental ela pode ser trabalhada em todos os anos né, de uma forma extracurricular [...] [P8]

Ah... eu acho que a questão da preservação né? Sempre focar na preservação desses recursos ambientais, dos biomas, da fauna, da flora, de se manter, né? As espécies, a riqueza dessa biodiversidade que nós temos, focar nessa questão, e ter esses conteúdos a nível de [sic] Estado, regional eu acho que é bem bacana. [P5]

Em nossa última questão, perguntamos aos professores sobre como deveriam ser tratados os conteúdos curriculares para a inserção da EA na escola. Nenhum dos entrevistados indicou uma organização metodológica para tal. Vejamos algumas de suas respostas:

\begin{abstract}
A educação ambiental ela vem como tema transversal né, é então eu acho que todo conteúdo que a gente pensa, toda aula que eu penso ou toda aula que eu organizo falando de mim né, mas em alguns pontos como eu acho que devem ser feito a gente tem que pensar, qual a importância desse conteúdo pro dia a dia, qual a importância desse assunto pra entender o ambiente, a natureza né, e como fazer para que meu aluno perceba isso, então as vezes um único exemplo simples, uma única historinha que eu conto já serve [...]. [P1]
\end{abstract}

Se nós tivéssemos conteúdos curriculares adequados, para isso ser trabalhado na escola e um tempo maior pra ser trabalhado, seria muito mais vantajoso para escola, para o aluno, para a questão da educação ambiental escolar, a gente deveria ter um tempo maior e a gente também deveria ter a questão desses currículos, é desses conteúdos curriculares produzidos com mais especificidade. [P7]

Sobre a seleção dos conteúdos curriculares fundamentais para a EA escolar e como deveriam ser tratados, Saviani (2003) nos traz uma importante contribuição: o processo de 'seleção do conhecimento' a ser incorporado ao currículo não deve ocorrer de maneira aleatória, mas de acordo com o que é necessário ao ser humano conhecer para enfrentar os problemas que a realidade apresenta.

Além disso, a produção social, o modo pelo qual os seres humanos produzem e reproduzem suas existências, está sempre mediada por determinada forma histórica de sociedade, pois "[...] toda produção é apropriação da natureza pelo indivíduo no interior de e mediada por uma determinada forma de sociedade" (MARX, 2011, p. 43). Os conteúdos são, portanto, as formas de apropriação da natureza pelo indivíduo, as formas de mediação da natureza pela sociedade e a posição do indivíduo na sociedade.

A premissa de que, para compreendermos o movimento real da sociedade (incluindo-se, é claro, a problemática socioambiental) devemos investigar além dos 
aspectos naturais e/ou biologicistas, econômicos, políticos, jurídicos, religiosos, culturais - em suma, ideológicos - recai sobre a advertência de que devemos investigar a forma pela qual homens e mulheres produzem a vida, relacionando-se uns com os outros, assim como a natureza, e, portanto, a realidade socioeconômica/ambiental surge como possível pressuposto pelo qual devemos iniciar o estudo de qualquer forma histórica de sociedade, e isso não permite que relacionemos a análise das relações ambiente/sociedade ao determinante reducionista (LARA, 2017).

Desse modo, é importante pensar na EA na escola a partir dos conteúdos científicos, filosóficos e artísticos, e na simultaneidade desses conteúdos como dados da realidade, isto é, é preciso assegurar na organização curricular a visão de totalidade, que comporta o particular e o universal, estabelecendo relações entre os diferentes conteúdos, ou seja, “[...] trata-se de, por meio da socialização dos conteúdos das diferentes áreas do conhecimento, permitir ao aluno que aprofunde sua compreensão acerca da realidade" (GAMA; DUARTE, 2017 , p. 524), principalmente no que diz respeito às questões socioambientais.

Ao indicarem como conteúdos possíveis para o trabalho com a EA apenas aqueles que tratam de aspectos naturais do ambiente, os professores participantes confirmam as duas concepções de EA identificadas inicialmente: a conservacionista e a pragmática, que não consideram o ambiente articulado às condições sociais, às relações de poder e ao processo de dominação. A nosso ver, essas concepções identificadas entre os professores, não permitem que eles vislumbrem possibilidades para trabalhar a EA a partir de um rol maior de conteúdo, não apenas os biologizantes.

Assim, a problematização da realidade pelo professor como parte do método da prática pedagógica é fundamental, pois a seleção do conhecimento que se vincula à definição dos objetivos de ensino - neste caso, a EA -, implica definir prioridades: distinguindo o que é principal e o que é secundário, o que é ditado “[...] pelas condições da situação existencial concreta em que vive o homem" (SAVIANI, 2003, p. 39).

Deste modo, consideramos, com relação à seleção de conteúdos para o trabalho com a EA, que todo conteúdo necessário para compreender um problema socioambiental em sua totalidade, seja ele da Biologia, da Química, Geografia, História ou qualquer outra área do conhecimento, pode ser entendido como um conteúdo da EA, desde que este seja contextualizado e problematizado pelos professores, a fim de que sua apropriação, pelos alunos, possibilite-os enfrentar os problemas que a realidade apresenta.

Em relação às formas de transmissão e assimilação do conhecimento, Saviani (2003) aponta ser fundamental que o conhecimento seja ministrado e sequenciado de forma a garantir a automatização de mecanismos que permitam a tomada de uma posição crítica que só pode ser propiciada pelo domínio de determinados procedimentos.

Nesse sentido, segundo Marsiglia (2011), a PHC desenvolve uma reflexão com posições concretas, de forma que a crítica a outras correntes teóricas não seja esvaziada pela falta de soluções e organização metodológica do pensamento. Assim, essa proposta pedagógica consiste em cinco momentos didáticos interdependentes: ponto de partida da prática educativa (prática social), problematização, instrumentalização, catarse e ponto de chegada da prática educativa (prática social qualitativamente superior) (SAVIANI, 2008). Diversos autores têm apresentado e discutido propostas de trabalho baseadas nesses cinco momentos, entre eles, citamos Santos (2005), que trata do Ensino de Ciências na abordagem histórico-crítica. 
No entanto, é preciso ressaltar que este estudo pretende apenas indicar um caminho metodológico, uma possibilidade de prática pedagógica da EA, baseada na PHC. Com isso, não esperamos oferecer um receituário, mas entendemos que a compreensão da teoria e a adoção dessa concepção pedagógica pelos professores podem contribuir para a inserção da EA no currículo escolar, como uma atividade nuclear, do modo como a consideramos ser realmente efetiva.

\section{Considerações finais}

A despeito dos retrocessos observados recentemente no campo ambiental no Brasil, como o silêncio da EA identificado nas políticas educacionais atuais, vimos, a partir dos resultados deste estudo, que EA ainda está presente nas escolas.

Com o objetivo analisar a Educação Ambiental (EA) nas escolas públicas estaduais de Ivinhema, MS, principalmente, sua relação com os conteúdos curriculares, o presente estudo trouxe como argumento a necessidade de superar a fragilidade das práticas identificadas por diferentes estudos e tratá-la como uma atividade nuclear do currículo.

A partir dos dados coletados e analisados, podemos dizer que a prática educativa ambiental sob a metodologia de projetos parece ter sido deixada de lado. No entanto, apesar de a abordagem da EA ter passado a ocorrer no interior das disciplinas, no trabalho com os seus conteúdos, como nos apontaram os professores participantes, não identificamos uma organização metodológica para tal. Além disso, os professores participantes não demonstraram ter uma compreensão clara do papel dos conteúdos curriculares para a EA, nem sobre quais seriam esses conteúdos e como eles devem ser tratados. O acesso e a apropriação dessas ferramentas culturais, os conteúdos, possibilitam às camadas populares lutarem pela superação das condições de opressão em que vivem, incluindo-se aí as condições socioambientais, ou seja, trazendo essa discussão para a EA, consideramos que, com o conhecimento adquirido e problematizado na escola, os educandos podem compreender de uma forma mais ampla os variados fatores que incidem e/ou constituem um problema socioambiental, sejam eles naturais, econômicos, políticos, etc.

Diante disso, a EA, que podemos chamar de histórico-crítica, discute sua inserção na escola voltada para o processo de formação plena de indivíduos singulares que, ao se apropriarem criticamente dos elementos da cultura, em especial no que diz respeito às relações das sociedades com o ambiente em que vivem, têm condições objetivas de se formarem para uma prática social transformadora. A PHC traz, então, entre outras contribuições, a necessidade de a EA escolar resgatar a importância dos conteúdos curriculares em seu processo educativo, propondo, inclusive, um caminho metodológico para isso.

Por fim, apontamos a importância de se (re)pensar o currículo de forma mais aprofundada, crítica, e não apenas como 'grade curricular' ou lista de disciplinas. Como nos indicam Gama e Duarte (2017), o trato com o conhecimento na escola, embora requeira a sistematização de sequências dos conteúdos curriculares, não deve ser visto de maneira linear, em sucessivas etapas às quais não se retorna, mas um processo no qual vão se ampliando as referências acerca do objeto, ou seja, a apreensão das múltiplas determinações. Desse modo, ainda segundo os autores, além 
da incorporação de novos conteúdos, o que mudaria de uma etapa de ensino para outra "[...] seria a ampliação das referências sobre aspectos da realidade já estudados que, dessa maneira, serão compreendidos pelos alunos de forma cada vez mais aprofundada e complexa" (GAMA; DUARTE, 2017, p. 525). Por fim, nesse movimento, são enriquecidas as determinações sobre os objetos estudados, avançando-se na qualidade do conhecimento apropriado e objetivado. O currículo, por sua vez, deverá traduzir essa organização, dispondo o tempo, os agentes e os instrumentos necessários para que se alcance a aprendizagem (SAVIANI, 2003).

\section{Referências}

100 DIAS sem educação ambiental. Observatório da Educação Ambiental: Observare, 8 abr. 2019. Disponível em: https://cutt.ly/yW5rkpo. Acesso em: 10 out. 2020.

AGUDO, M. M. A maior flor do mundo de José Saramago e a educação ambiental na escola. 2013. Dissertação (Mestrado em Educação para a Ciência) - Faculdade de Ciências, Universidade Estadual Paulista, Bauru, 2013. Disponível em: https://cutt.ly/yW5tqvy. Acesso em: 15 set. 2021.

BARCELOS, V. Navegando e traçando mapas: uma contribuição à pesquisa em educação ambiental. In: GALIAZZI, C. FREITAS, J. V. (org.). Metodologias emergentes de pesquisa em educação ambiental. 2. ed. Ijuí: Unijuí, 2007. p. 63-84.

BASSO, I. S. Significado e sentido do trabalho docente. Cadernos Cedes, Campinas, v. 19, n. 44, p. 19-32, 1998. DOI: https://doi.org/dkxq4j.

BRASIL. [Constituição (1988)]. Constituição da República Federativa do Brasil de 1988. Brasília, DF: Presidência da República, [1988]. Disponível em: https://cutt.ly/6W5pi8Y. Acesso em: 15 set. 2021.

BRASIL. Lei no 6.938, de 31 de agosto de 1981. Dispõe sobre a política nacional do meio ambiente, seus fins e mecanismos de formulação e aplicação, e dá outras providências. Brasília: Presidência da República, 1981. Disponível em: https://cutt.ly/YW5phMX. Acesso em: 15 set. 2021.

BRASIL. Lei no 9.394, de 20 de dezembro de 1996. Estabelece as diretrizes e bases da educação nacional. Brasília: Presidência da República, 1996. Disponível em: https://cutt.ly/7W5pmqw. Acesso em: 15 set. 2021.

BRASIL. Lei no 9.795, de 27 de abril de 1999. Dispõe sobre a educação ambiental, institui a política nacional de educação ambiental e dá outras providências. Brasília: Presidência da República, 1999. Disponível em: https://cutt.ly/8W5pS2z. Acesso em: 15 set. 2021.

BRASIL. Lei no 10.172, de 9 de janeiro de 2001. Aprova o plano nacional de educação e dá outras providências. Brasília: Presidência da República, 2001. Disponível em: https://cutt.ly/YW5pKIW. Acesso em: 15 set. 2021.

BRASIL. Lei no 13.005/2014. Aprova o Plano Nacional de Educação - PNE e dá outras providências. Brasília: Presidência da República, 2014. Disponível em: https://cutt.ly/jW5pNxo. Acesso em: 15 set. 2021.

BRASIL. Resolução no 2, de 15 de junho de 2012. Estabelece as diretrizes curriculares nacionais para a educação ambiental. Brasília: MEC, 2012. Disponível em: https://cutt.ly/DW5p5PO. Acesso em: 15 set. 2021.

BRASIL. Resolução CNE/CP no 2, de 22 de dezembro de 2017. Institui e orienta a implantação da base nacional comum curricular, a ser respeitada obrigatoriamente ao longo das etapas e respectivas modalidades no âmbito da educação básica. [Brasília]: MEC, 2017. Disponível em: https://cutt.ly/WW5aukM. Acesso em: 15 set. 2021. 
BRASIL. Ministério da educação. Proposta de diretrizes curriculares nacionais para a educação ambiental. [Brasília: MEC, 2002]. Disponível em: http://portal.mec.gov.br/dmdocuments/ publicacao13.pdf . Acesso em: 4 out. 2021.

CHIZZOTTI, A. Pesquisa em ciências humanas e sociais. São Paulo: Cortez, 2001.

CRUZ, L. G. C. Políticas públicas de educação ambiental: um estudo sobre a agenda 21 escolar. 2014. Tese (Doutorado em Educação Para a Ciência) - Faculdade de Ciências, Universidade Estadual Paulista, Bauru, 2014. Disponível em: https://cutt.ly/NW5a60z. Acesso em: 15 set. 2021.

DEVECHI, C. P. V.; TREVISAN, A. L. Sobre a proximidade do senso comum das pesquisas qualitativas em educação: positividade ou simples decadência? Revista Brasileira de Educação, Rio de Janeiro, v. 15, n. 43, p. 148-201, 2010. DOI: https://doi.org/d4v8jt.

FACCI, M. G. D. Valorização ou esvaziamento do trabalho do professor: um estudo crítico comparativo da teoria do professor reflexivo, do construtivismo e da psicologia vigotskiana. Campinas: Autores Associados, 2004.

FESTOZO, M. B. A educação ambiental na formação de professores: horizontes para a participação social. 2015. Tese (Doutorado em Educação para a Ciência) - Faculdade de Ciências, Universidade Estadual Paulista, Bauru, 2015.

FIGUEIREDO, P. Formação e atuação de professores em educação ambiental. 2014. Dissertação (Mestrado em Educação para a Ciência) - Faculdade de Ciências, Universidade Estadual Paulista, Bauru, 2014. Disponível em: https://cutt.ly/2W5dGK0. Acesso em: 15 set. 2021.

FRIZZO, T. C. E.; CARVALHO, I. C. M. Políticas públicas atuais no Brasil: o silêncio da educação ambiental. REMEA, Rio Grande, ed. esp. 1, p. 115-127, 2018. DOI: https://doi.org/gv53.

GAMA, C. N.; DUARTE, N. Concepção de currículo em Dermeval Saviani e suas relações com a categoria marxista de liberdade. Interface, Botucatu, v. 21, n. 62, p. 521-530, 2017. DOI: https:// doi.org/gv54.

LARA, R. História e práxis social: introdução aos complexos categoriais do ser social. Bauru: Canal 6, 2017.

LAYRARGUES, P. P.; LIMA, G. F. C. As macrotendências político-pedagógicas da educação ambiental brasileira. Ambiente \& Sociedade, São Paulo, v. 17, n. 1. p. 23-40, 2014. Disponível em: https://cutt.ly/iW5gyVZ. Acesso em: 15 jul. 2020.

MAIA, J. S. S. Educação ambiental crítica e formação de professores. 2011. Tese (Doutorado em Educação para a Ciência) - Faculdade de Ciências, Universidade Estadual Paulista, Bauru, 2011. Disponível em: https://cutt.ly/XW5gGAx. Acesso em: 15 jul. 2020.

MAGALHÃES, C. Estágio: superação do espontaneísmo e docência na educação infantil. Olhar de professor, Ponta Grossa, v. 22, p. 1-14, 2019. DOI: https://doi.org/gv55.

MALANCHEN, J. Currículo e pedagogia histórico-crítica: a defesa da universalidade dos conteúdos escolares. In: ANPED SUL, 10., Florianópolis. [2014]. Disponível em: https://cutt.ly/ iW5jXeN. Acesso em: 15 set. 2021.

MARSIGLIA, A. C. G. A prática pedagógica na perspectiva da pedagogia histórico-crítica. In: MARSIGLIA, A. C. G. (org.). Pedagogia histórico-crítica: 30 anos. Campinas: Autores Associados, 2011. p. 101-120.

MARX, K. Grundisse: manuscritos econômicos de 1857-1858: esboços da crítica da economia política. São Paulo: Boitempo; Rio de Janeiro: Ed. UFRJ, 2011.

MATO GROSSO DO SUL. Lei no 5.287, de 13 de dezembro de 2018. Institui a política estadual de educação ambiental, e dá outras providências. [S. I.: s. n.], 2018. Disponível em: https://cutt.ly/ VW5XPk1. Acesso em: 15 set. 2021. 
MATO GROSSO DO SUL. Resolução no 3.322, de 13 de setembro de 2017. Dispõe sobre a oferta da educação ambiental nas escolas da rede estadual de ensino de Mato Grosso do Sul. [S. I.: s. n.], 2018. Diário Oficial Mato Grosso do Sul, Campo Grande, n. 9494, p. 6, 15 set. 2017. Disponível em: https://cutt.ly/JW5XL3z. Acesso em: 15 set. 2021.

MELLO, S. A. Linguagem, consciência e alienação: o óbvio como obstáculo ao desenvolvimento da consciência crítica. Marília: Unesp Publicações, 2000.

MENDES, C. B. Influências de instituições externas à escola pública: privatização do ensino a partir da educação ambiental? 2015. Dissertação (Mestrado em Educação para a Ciência) - Faculdade de Ciências, Universidade Estadual Paulista, Bauru, 2015. Disponível em: https://cutt.ly/ eW5CWsE. Acesso em: 15 set. 2021.

MINAYO, M. C. S. O desafio do conhecimento: pesquisa qualitativa em saúde. 5. ed. São Paulo: Hucitec: Abrasco, 1998.

MINAYO, M. C. S. O desafio da pesquisa social. In: MINAYO, M.C.S. (org.). Pesquisa social: teoria, método e criatividade. 27. ed. Petrópolis: Vozes, 2008. p. 9-29.

OLIVEIRA, L.; NEIMAN, Z. Educação ambiental no âmbito escolar: análise do processo de elaboração e aprovação da base nacional comum curricular (BNCC). RevBEA, São Paulo, v. 15, n. 3, p. 36-52, 2020. DOI: https://doi.org/gv58.

REIGOTA, M. Educação ambiental e representação social. São Paulo: Cortez, 1995.

SANTOS, C. S. Ensino de ciências: abordagem histórico-crítica. Campinas: Autores Associados, 2005.

SAVIANI, D. Escola e democracia. 40. ed. Campinas: Autores Associados, 2008.

SAVIANI, D. Pedagogia histórico-crítica: primeiras aproximações. 8. ed. Campinas: Autores Associados, 2003.

SILVA, S. N.; LOUREIRO, C. F. B. As vozes de professores-pesquisadores do campo da educação ambiental sobre a base nacional comum curricular (BNCC): educação infantil ao ensino fundamental. Ciência \& Educação, Bauru, v. 26, e20004, 2020. DOI: https://doi.org/gv59.

SOUZA, D. C. A educação ambiental crítica e sua construção na escola pública: compreendendo contradições pelos caminhos da formação de professores. 2014. Tese (Doutorado em Educação para a Ciência) - Faculdade de Ciências, Universidade Estadual Paulista, Bauru, 2014. Disponível em: https://repositorio.unesp.br/handle/11449/110907. Acesso em: 15 set. 2021.

TEIXEIRA, L. A. Formação do educador ambiental: reflexões de um professor da escola pública. 2013. Tese (Doutorado em Educação para a Ciência) - Faculdade de Ciências, Universidade Estadual Paulista, Bauru, 2013. Disponível em: https://repositorio.unesp.br/ handle/11449/102054. Acesso em: 15 set. 2021.

TOZONI-REIS, M. F. C. Educação ambiental na escola básica: reflexões sobre a prática dos professores. Revista Contemporânea de Educação, Rio de Janeiro, v. 7, n. 14, p. 276-288, 2012. Disponível em: https://cutt.ly/IW5MtJn. Acesso em: 15 set. 2021.

TOZONI-REIS, M. F. C.; MUNHOZ, R. H. A inserção da educação ambiental na educação básica: que fontes de informação os professores utilizam para sua formação? Ciência \& Educação, Bauru, v. 19, n. 2, p. 359-377, 2013. DOI: https://doi.org/gv6b.

TRAJBER, R.; MENDONÇA, P. R. (org.). O que fazem as escolas que dizem que fazem educação ambiental. Brasília: MEC, 2006.

VEIGA, A.; AMORIM, E.; BLANCO, M. Um retrato da presença da educação ambiental no ensino fundamental brasileiro: o percurso de um processo acelerado de expansão. Brasília: INEP, 2006. 